\title{
Beyond Homophily: A Decade of Advances in Understanding Peer Influence Processes
}

\author{
Whitney A. Brechwald and \\ Duke University \\ Mitchell J. Prinstein \\ University of North Carolina at Chapel Hill
}

\begin{abstract}
This article reviews empirical and theoretical contributions to a multidisciplinary understanding of peer influence processes in adolescence over the past decade. Five themes of peer influence research from this decade were identified, including a broadening of the range of behaviors for which peer influence occurs, distinguishing the sources of influence, probing the conditions under which influence is amplified/attenuated (moderators), testing theoretically based models of peer influence processes (mechanisms), and preliminary exploration of behavioral neuroscience perspectives on peer influence. This review highlights advances in each of these areas, underscores gaps in current knowledge of peer influence processes, and outlines important challenges for future research.
\end{abstract}

Research over the past several decades consistently has revealed an important, yet deceptively simple finding regarding adolescent development: adolescents' behaviors and attitudes are remarkably similar to the behaviors and attitudes of their friends. Many years ago, a set of distinct, yet inter-related processes (i.e., homophily effects) was proposed to help explain this important phenomenon (Kandel, 1978). Homophily theories suggested that such similarities between adolescents and their friends are due to youths' initial tendencies to affiliate with friends who already possess similar behavioral proclivities and like-minded attitudes (i.e., selection effects), as well as a tendency for adolescents' and their friends' behavior and attitudes to become more similar over time (i.e., socialization effects). Studies determining the presence of selection and/or socialization effects for a range of adolescent behaviors (including aggressive and health-risk behaviors most frequently) dominated the peer influence field over the subsequent decades, largely yielding general support for the relevance of both processes.

In this review, and in much of the literature that has emerged from the past decade, peer influence is defined as a phenomenon characterized by the presence of both selection and socialization. Indeed, recent research has placed particular emphasis on further understanding the dynamic, reciprocal associations between selection and socialization in adolescent peer relations (e.g., Dishion \& Owen, 2002; Hall \& Valente, 2007; Popp, Laursen, Kerr, Stattin, \& Burk, 2008). However, consistent with the emphasis of empirical work in the past decade, this review will focus predominantly on socialization processes. It should be noted at the outset that the research designs and statistical methods applied to the study of peer influence in the past decade have continued to vary considerably. Although 
many studies have engaged in systematic measurement of peer-reported (i.e., actual) and/or target adolescent-reported (i.e., perceived) peer behaviors across time as indicators of target adolescent behavioral change, a number of researchers operationalize peer "influence" as adolescents' own reports of how much they feel influenced by agemates. Although this latter conceptualization and measurement of influence does provide information about adolescents' experiences with their peers, the current review largely focuses on research that has examined both perceptions of peers' behavior and actual, peer-reported behaviors in the influence process.

At least five main themes have emerged in the past decade within the peer influence literature. The first two of these themes have continued the largely descriptive research that dominated the field for the past several decades, addressing the parameters of peer influence effects. Specifically, while prior work has focused predominantly on peer socialization of deviant and aggressive behaviors, an initial theme of work in the past decade has applied peer influence theories to the study of other risk behaviors or domains of adjustment that previously had not been conceptualized as susceptible to socialization processes. Second, the past decade has witnessed notable advances in research on potential sources of peer influence (e.g., romantic partners, best friends, larger peer networks). Three additional themes have emerged in the past decade of peer influence research; each of these areas of investigation has addressed "how" or "why" peer socialization happens. For instance, a third theme has reflected progress in our understanding of the mechanisms (including mediators) of peer socialization processes. This emphasis has benefitted from expansions of rich theoretical perspectives previously articulated by developmental and social psychologists. Fourth, research has begun to focus on moderators that may magnify or mitigate peer influence effects. Finally, progress in the field of behavioral neuroscience has offered interesting preliminary insight into how biological models may be relevant to peer selection and socialization.

This review highlights many of the exciting empirical and theoretical findings from the past 10 years in five sections that parallel the major advances in peer influence research outlined above. At the end of each section, a reflective synthesis of recent contributions is offered with an emphasis on emerging directions and questions for the field of peer influence research.

\section{BEHAVIORS RELEVANT TO PEER INFLUENCE}

The majority of research examining peer influence effects in prior decades has focused on socialization of antisocial, deviant, and health-risk behaviors. Work in these behavioral domains has continued into the most recent decade, spurred by robust and consistent support for the role of peers in alcohol use (for a review, see Bosari \& Carey, 2001), smoking (for a review, see Kobus, 2003), and aggressive and/or illegal behaviors (e.g., Dishion, Eddy, Haas, Li, \& Spracklen, 1997). This emphasis is understandable, given the physical and mental health implications of these behaviors for adolescents and the impact of antisocial activities on public well-being.

However, recent work has revealed peer socialization effects in other domains of adjustment. For instance, recent work has indicated that internalizing behaviors, such as nonsuicidal self-injury (Heilbron \& Prinstein, 2008; Nock \& Prinstein, 2005; Prinstein, Guerry, Browne, Rancourt, \& Nock, 2009) and depressive symptoms (Prinstein, 2007; Stevens \& Prinstein, 2005; Van Zalk, Kerr, Branje, Stattin, \& Meeus, 2010), also are susceptible to influence processes. Research also has suggested that eating problems and body image concerns in adolescent girls may be transmitted by peers (e.g., Hutchinson \& Rapee, 2007), although this behavioral domain is in need of additional longitudinal work. 
Further, peer influence effects appear to be relevant to adolescents' values and beliefs, such as academic motivation and achievement (Ryan, 2001; Wentzel, Barry, \& Caldwell, 2004) and prejudiced attitudes (Poteat, 2007; Poteat, Espelage, \& Green, 2007). With growing clarity, it appears that the reach of peer influence processes is broad, and the implications of the behavior formation and change motivated by peers during the formative adolescent years are potentially quite far-reaching.

The last decade also has produced sorely needed research to suggest that peer influence effects are relevant to the development of healthy behaviors (e.g., prosocial behavior; Barry \& Wentzel, 2006). Peer socialization processes also may provide potential protection from maladaptative outcomes (Adamczyk-Robinette, Fletcher, \& Wright, 2002; Prinstein, Boergers, \& Spirito, 2001).

\section{Synthesis and Future Directions}

As research on the behaviors that may be susceptible to peer influence continues to progress, it has become evident that socialization by peers is a normative and perhaps even adaptive phenomenon that requires study from broader developmental and sociological perspectives (Allen \& Antonishak, 2008; Brown, Bakken, Ameringer, \& Mahon, 2008). Adolescents' reliance on their peers to understand acceptable and desired behaviors (at least in the peer context) likely reflects successful individuation from adult values and healthy identity development (Brown, 1990; Harter, Stocker, \& Robinson, 1996). Numerous public health campaigns have recognized the potential power of peers to motivate adolescents toward adaptive behavior and healthy development (e.g., "Students Against Drunk Driving"; the Office of National Drug Control Policy's "Above the Influence" campaign; American Legacy Foundations' "The Truth" antismoking campaign). Moreover, research in other fields has recognized that peer influence effects are complex and far-reaching (e.g., contagion of offensives among prison inmates; Bayer, Pintoff, \& Pozen, 2004; e.g., pertaining to happiness, loneliness; Fowler \& Christakis, 2009). Exciting work in the coming decades will continue to understand peer socialization as a normative phenomenon, with emphases on its ubiquity and the processes that contribute to peers' broad socialization influence on adolescents' development.

In particular, research aimed toward understanding the broad applicability of peer influence effects may benefit from more creative and expansive models of socialization. To date, most of all the research on peer influence has adopted a modeling or imitation perspective, using peers' engagement in a specific behavior (i.e., behavior X) as a predictor of adolescents' own engagement in the same behavior (i.e., behavior X). However, it is likely that adolescents' socialization occurs not only through modeling or imitation, but also through social comparison and/or behavior approximation effects. It is likely that adolescents who believe their peers engage in a specific behavior (i.e., behavior $\mathrm{X}$ ) are more likely to engage in a related or thematically similar behavior (i.e., behavior Y). For instance, in our lab preliminary data suggested that adolescents' best friends' engagement in binge eating behavior was associated with adolescents' own adoption of negative body-related cognitions (e.g., body dissatisfaction), but not binge eating per se (Rancourt \& Prinstein, 2008). Alternatively, it may be that adolescents influence one another's behavior due to comparison on related attributes. In the same study, our findings revealed that adolescents who deviated from their best friends in pubertal development were more likely than those similarly developed to their friends to engage in dieting behaviors (Rancourt \& Prinstein, 2008). These types of processes are rarely examined, yet reflect important ways in which adolescents' attitudes and behaviors are influenced by their peers. 


\section{SOURCES OF PEER INFLUENCE}

A second substantial advance in the past decade has been a growing recognition of the many different peers-individuals and groups - that may exert powerful socialization effects on adolescents' behaviors and attitudes. For many years, adolescent peer influence was measured by asking adolescents themselves to report the extent to which their "peers" engaged in specific behaviors. Advances in the broader peer relations literature clearly have since delineated a multitude of distinct, salient peer relationships (Rubin et al., 2006); past work that did not specifically define who these "peers" were had a limited picture of the specific relationships that are most influential. Given the restricted focus of prior work, it is especially exciting that research in the past decade has begun to explore more thoroughly both the best friend relationships and other social contexts in which peer socialization may occur. For instance, recent work has examined peer selection and socialization within romantic relationships (Simon, Aikins, \& Prinstein, 2008) and sibling relationships (Stormshak, Comeau, \& Shepard, 2004; van der Vorst, Engels, Meeus, Dekovic, \& Van Leeuwe, 2007). In addition, research has begun to reflect findings on adolescent friendship suggesting that most dyadic relationships are nested within larger networks, or cliques, of friendships. The recent availability of sophisticated quantitative tools such as social network analysis also has allowed for a more thorough study of these cliques and the peer influence processes that may occur within them (e.g., Burk, Steglich, \& Snijders, 2007; Laursen et al., 2008).

\section{Synthesis and Future Directions}

The continued study of peer influence within multiple peer contexts surely will represent a large focus of work in the coming decade. Socialization within peer cliques, in particular, has become a very popular focus of recent work. This research benefits from the recognition that adolescents and their relationships reside within cliques, crowds, and larger networks of friends, and many best friend interactions (i.e., including those that may be influential) occur in the presence of many other friends who may alter the potential for best friend socialization. This is especially relevant given the volatility of close friend relations among adolescents. Although the designation of a single "close," or "best" friend may change rapidly, members of a broader peer clique may be more stable (Urberg, Degirmencioglu, Tolson, \& Halliday-Scher, 1995). Understanding peer influence in a clique context-and, when possible, attempting to compare effects of groups and dyads (see Popp et al., 2008) thus offers great potential to understand socialization effects more meaningfully. However, it will be important for future research to retain adequate emphasis on theory and use caution in allowing statistical applications to exclusively dictate the composition of adolescents' peer cliques. For some behaviors (perhaps deviant behavior, for instance), tangentially related peers, connected to one another within a broad, diffuse network, may have the potential to influence the behavior of others. In fact, for some behaviors, peers with whom adolescents do not have any direct relationship still may be highly influential (i.e., see research on media influence effects; Dubow, Huesmann, \& Greenwood, 2007). However, distant peer affiliations may be less relevant for covert or internalized attitudes/behaviors (e.g., depressive symptoms).

In addition to the need for a careful integration of theoretical and statistical advances in studying multiple socialization influencers, there is a strong need to consider potentially conflicting socialization influences that adolescents may experience across distinct peer contexts and understand how youth reconcile the multiple influencing sources in their lives. It is quite likely that adolescents receive different, but perhaps equally powerful messages from their close friends, romantic partners, popular peer role models, enemies, and clique or crowd affiliates. Recent work, for example, found that adolescents who identified with multiple peer crowds with competing norms for substance use were less likely to engage in 
norm-consistent behavior, but more likely to adhere to substance use norms if they reported identification with several groups with congruent norms (Verkooijen, de Vries, \& Nielsen, 2007). However, currently, little is known regarding the processes that guide adolescent decision-making when they are confronted with divergent socialization agents.

\section{PEER INFLUENCE MECHANISMS}

One of the most notable contributions of peer influence research in the past decade has begun to elucidate how or why adolescents may conform to their peers. Given that it likely is difficult to prevent adolescents from affiliating with peers that may exert negative influences, the study of mechanisms is critical for prevention efforts. By understanding why adolescents conform to peers, it may be possible to develop preventive measures that alternatively address the psychological motivations that currently lead to conformity. The mechanisms reviewed below may also be conceptualized and analyzed as mediators, and this term has been included in the review when used by investigators.

A few dominant theoretical perspectives have guided recent work on mechanisms of influence among adolescent peers, and a brief discussion of these approaches is necessary for understanding the theoretical underpinnings of the last decade of research. First, developmental theories indicate that the adolescent transition is marked by increases in (1) the frequency of peer interactions (Brown, Dolcini, \& Leventhal, 1997); (2) the adoption of increasingly sophisticated interpersonal behaviors, new social roles, and novel experiences (Brown, 1990); (3) adolescents' motivation to develop a stable sense of identity (i.e., selfconcept; Harter et al., 1996); and (4) youths' reliance on peer feedback (and their perceived peer status) as a source of identity and self-evaluation (a process known as "reflected appraisal"; Hergovich, Sirsch, \& Felinger, 2002). In short, the peer context is especially salient in adolescence, and success among peers becomes paramount.

The fundamental assumption that adolescents are particularly attuned to and motivated by positive regard and belongingness in the peer context provides a basis for two complementary theoretical models that help to explain peer socialization effects. First, social learning theories suggest that within a salient social context, individuals adopt new behaviors through modeling, social reward and punishment, and vicarious reinforcement (via observational learning) of valued peers (Bandura, 1986). For example, adolescents who observe that popular students drink alcohol will be motivated to conform to these behaviors in pursuit of similar status among peers (i.e., a social reward), particularly if adolescents receive extrinsic social reinforcement for doing so. Second, identity-based theories discussed largely within the social psychology literature suggest that emulation of valued or idealized others' behavior and adherence to perceived social norms within a valued reference group help confer a favorable sense of self; the adoption of a favorable sense of self is intrinsically rewarding (Abrams \& Hogg, 1990; Festinger, 1954). In sum, theories suggest that adolescents increasingly invest in peers as primary sources of social and emotional support while simultaneously using feedback and acceptance from their peers as bases for a sense of self-concept. By conforming to peers' behavior, adolescents engage in behaviors that (1) are associated with high peer status; (2) match the social norms of a valued or desired social group; (3) lead to extrinsic behavioral reinforcement within a social context; and (4) contribute to an intrinsically rewarding sense of a favorable self-identity. In the past decade, advances in work on peer influence have allowed for some preliminary examination of these ideas; each is discussed below.

\section{Peer Influence Mechanisms: Adolescents Engage in High-Status Behaviors}

Evidence from an exciting integration between peer influence research and recent innovative developments in the study of adolescent "peer-perceived popularity" (Cillessen \& Rose, 
2005; Parkhurst \& Hopmeyer, 1998) has suggested that peer influence indeed seems to be associated with behaviors linked to high-status peers. When conceptualizing peer status as a reputation-based measure reflecting dominance, positions on the social hierarchy, and access to resources, investigators revealed that many of the behaviors especially relevant to peer influence (i.e., aggressive and health-risk behaviors) are associated with high statusspecifically, popularity—among peers (Mayeux, Sandstrom, \& Cillessen, 2008; Prinstein, Meade, \& Cohen, 2003; Rancourt \& Prinstein, 2010). Affiliation with adolescents high in peer-perceived popularity and exposure to the behavioral norms of these peers are associated with increases in adolescents' own engagement in aggressive behavior (Prinstein \& Cillessen, 2003; Rose, Swenson, \& Waller, 2004) as well as several health-risk behaviors, including maladaptive weight-related behaviors (Rancourt \& Prinstein, 2010). Longitudinal work by Juvonen and Ho (2008) demonstrated that middle school students who associated peer-directed aggressive behavior with high social status (coolness) in the first semester of middle school demonstrated increased antisocial behavior in the second year at that school. In addition, research has revealed that adolescents are more likely to engage in these behaviors and endorse deviant-related attitudes if they believe that doing so has been endorsed by high-status peers (Cohen \& Prinstein, 2006). If adolescents are led to believe that these same deviant-related attitudes are endorsed by low-status peers, adolescents demonstrate anticonformity, adopting opposite-valenced attitudes (Cohen \& Prinstein, 2006). Related research suggests that failure to adhere to dominant or valued social norms may be met with social punishment in the form of exclusion and rejection by peers (Juvonen \& Galvan, 2008).

\section{Peer Influence Mechanisms: Adolescents Engage in Behaviors That Match the Social Norms of a Valued or Desired Group}

Social psychologists' research convincingly has asserted that social norms are powerful regulators of adolescents' behavior and can explain peer influence effects (see Berger, 2008; Blanton \& Burkley, 2008; Prentice, 2008). Note, however, that although some evidence suggests that adolescents may be influenced toward behaviors that are associated with high status in the peer context, not all adolescents may value popular peers or desire identification with high-status individuals. Some adolescents may be especially influenced toward behaviors that are associated with social norms of peers who occupy a less central position within the larger peer network. For instance, work has suggested that youth with reputations of peer rejection and histories of aggressive behavior may be especially likely to affiliate with deviant peer groups, who actively reject the behavioral norms of the overall peer context and instead adopt a local set of social norms that may be more salient to these adolescents' identity development (Dishion, Burraston, \& Poulin, 2001; Killeya-Jones, Costanzo, Malone, Quinlan, \& Miller-Johnson, 2007). Other work has suggested that proximal norms mediate the association between global (i.e., broad) norms for a behavior and adolescents' own engagement in the behavior (Maddock \& Glanz, 2005). Moreover, some behaviors may be associated with high status only at a developmental level in which these behaviors are considered to be unique. For instance, Heilbron and Prinstein (2010) revealed that nonsuicidal self-injurious behaviors were concurrently associated with high peer status (both reputation- and preference-based popularity) in a sample of early adolescents, suggesting that these behaviors might be perceived as a feature of high-status peer groups in this particular context.

Social norms are in the eye of the beholder, founded primarily on adolescents' perceptions of one another's values and behaviors. Empirical work before and within this decade has revealed stronger associations between adolescents' behavior and their perception of their peers' behavioral norms (i.e., adolescents' own report of their peers' behavior), compared with the peers' actual (self-reported) behavior (see Prentice \& Miller, 1996). Exploration of 
actual and perceptive norms, and the relevance of each for influence processes, has appeared in this decade in the form of research on misperceptions of peer behavior, such as alcohol use (Perkins, Haines, \& Rice, 2005). Overestimates of behavior also have been found to mediate associations between peers' and adolescents' smoking behavior (Otten, Engels, \& Prinstein, 2009). These findings highlight the importance of considering social norm perceptions in tandem with actual norms. From an intervention standpoint, correction of erroneous perceptions may offer a fruitful redirection of peer influence in harmful behavioral domains; however, work from the past decade has suggested that successful application of this strategy may depend on such factors as the target adolescent population and the ability of the population to identify with the peers who exhibit the "corrected" norm (see Prentice, 2008, for a review).

\section{Peer Influence Mechanisms: Adolescents Engage in Behaviors That Are Reinforced by Peers}

Arguably, one of the most substantial contributions to empirical exploration of the mechanisms of peer influence has been research on deviancy training, an interactional process characterized by repeated peer reinforcement for talk about antisocial acts and attitudes (e.g., Dishion, Spracklen, Andrews, \& Patterson, 1996; Granic \& Dishion, 2003). Through careful observation of friendship dyads engaged in conversations, this research has demonstrated that peer reinforcement of antisocial behavior occurs through positive affective behaviors, such as smiling and laughing, in response to deviant talk. Among adolescent males at risk of antisocial outcomes, research before this decade had shown that this process is associated with increases in antisocial and health-risk behaviors, such as substance use and violence (e.g., Dishion et al., 1996). Ample work from the past 10 years has continued to examine this process as a key mechanism of contagion for antisocial or deviant behavior across gender and development. For instance, this work has suggested that deviancy training occurs in female adolescents, although to a lesser degree than among male adolescent dyads (Dishion, 2000; Piehler \& Dishion, 2007). The process also has been observed in children as young as kindergartners; work by Snyder has shown that engagement in deviancy training predicts escalations in conduct problems across elementary school (Snyder et al., 2005, 2008). Several studies from the maturing Oregon Youth Study sample have detected predictive effects of deviancy training in early adolescence on problematic behavior in late adolescence and young adulthood (Dishion, Nelson, Winter, \& Bullock, 2004; Dishion, Nelson, \& Yasui, 2005; Patterson, Dishion, \& Yoerger, 2000), suggesting that effects of deviancy training in adolescence persist beyond this developmental period.

The last decade also has witnessed increasingly complex examinations of related social interaction dynamics which may amplify social reinforcement influence mechanisms. Recent research using a dynamic systems framework has identified that among 14-year-old male dyads, highly organized or predictable dyadic social interactions (i.e., low levels of "entropy") interact with deviant talk to predict increases in deviant behavior in young adulthood (Dishion et al., 2004; Dishion, Piehler, \& Myers, 2008). Similarly, "dyadic mutuality," or the degree of reciprocity, harmony, and understanding shared by two friends, also appears to moderate the effects of deviant talk on problem behavior (Piehler \& Dishion, 2007). This work on interpersonal facets of influence mechanisms highlights the potential for relationship dynamics to function as both moderators and mediators of influence processes. 


\section{Peer Influence Mechanisms: Adolescents Engage in Behaviors That Contribute to a} Favorable Self-Identity

Research on the prototype/willingness model has suggested that peer conformity may foster a positive self-concept (Gibbons, Gerrard, \& Lane, 2003). According to the dual-process model, adolescents first determine the norms of relevant, or valued, peer groups (i.e., a role model) and establish which behaviors would be approved by these peers. This favorable evaluation increases the adolescent's intention to engage in the behavior(s); by aligning with the values of an admired peer, adolescents themselves develop a heightened sense of self. Behavioral willingness to engage in a particular (even risky) behavior is based on adolescents' perceptions that esteemed peers would likely approve.

\section{Synthesis and Future Directions}

Recent research has offered exceptional advances toward understanding "how" and "why" peer influence works. However, it will be important to recognize that a "once size fits all" approach likely will not be fruitful when applying theories toward understanding socialization of different behaviors. For instance, although many of the theories discussed above help to elucidate socialization of deviant or health-risk behaviors, it is difficult to successfully apply these same theories of other socialized behaviors, such as depressive symptoms. As compared with socialization of deviant behaviors, depression socialization may be motivated by distinct psychological functions (e.g., see self-verification theory; Swann, 1983; also see Coyne, 1999; Sacco, 1999). Alternately, peer influence may operate through reinforcements or norms within unique peer contexts. For instance, although depressive symptoms are unlikely reinforced within the larger peer group, socialization may confer unique benefits within close friendships or romantic relationships (see Rose, Carlson, \& Waller, 2007). Yet another possibility is that some behaviors are influenced by anticonformity processes. Although rarely studied, anticonformity is a powerful phenomenon that is directly the result of peer influence processes; however, adolescents may be less likely to realize that they are being influenced by peers because they are engaging in behavior that is the opposite of what the peer majority prefers. By engaging in behaviors that are opposed to the majority's values, adolescents believe they are signaling their individuality and freedom from concerns about their popularity.

\section{PEER INFLUENCE MODERATORS}

As with research on peer influence mechanisms, research in the past decade has begun to address important questions regarding moderators of the socialization process. Because preventing affiliation among teens is both improbable and potentially detrimental to healthy psychosocial development (see Hall \& Valente, 2007), avoiding negative effects of peer affiliation depends on understanding the factors that increase susceptibility or vulnerability to peer influence. Although research on peer influence moderators remains relatively rare, this has been a rapidly growing area of work in the past decade.

For the purpose of this review, it is useful to describe these moderators as four "levels" or classes of variables (Hartup, 2005; Prinstein, 2007). First, characteristics of the influenced adolescent (i.e., the target adolescent) may alter susceptibility or resistance to peer influence. Second, features of the influence source (the influencing peer) may function to moderate influence effects. Third, the type or nature of the relationship between the target and the influencer may be relevant to the influence process. And finally, the type of behavior in question, such as deviant, neutral, or prosocial, also may impact susceptibility. Not surprisingly, these moderators also interact with one another both across and within levels of analysis (see Dishion \& Dodge, 2005; Hartup, 2005; Lavallee, Bierman, \& Nix, 2005). 


\section{Peer Influence Moderators: Target Adolescent Characteristics}

As compared with other factors that may moderate the potency of peer socialization effects, characteristics of the individual target adolescent have been studied most frequently. Initial work examined simple demographic variables (e.g., gender, age) that may affect peer influence; a trend to continue exploring this question continued in the most recent decade. Still, results have been equivocal, suggesting a need for more complex or theoretically informed questions.

For instance, the examination of gender as a moderator of peer socialization effects suggested that gender may prove relevant only within more complex two- and three-way interaction terms that also consider age and the specific behavior being influenced. In the past decade, close friend influence effects for substance use (Erickson, Crosnoe, \& Dombusch, 2000) and roommate socialization of binge drinking (Duncan, Boisjoly, Kremer, Levy, \& Eccles, 2005) have been found for male, but not female, adolescents. In an examination of the moderating effects of parental support and discipline on peer influence of alcohol use, Marshal and Chassin (2000) found that parental intervention reduced susceptibility to influence for girls, but amplified influence effects for boys of the same age. Gender differences in patterns of moderator relationships also were found in research on depression contagion, yet with different results (Prinstein, 2007; Stevens \& Prinstein, 2005).

Within the past 10 years, some interesting work examining age-related correlates have yielded a more consistent set of findings. For instance, recent work has suggested that vulnerability to socialization might be a function of developmentally normative psychosocial maturation, including identity development. Findings regarding age-related vulnerabilities to peer influence (Monahan, Steinberg, \& Cauffman, 2009; Steinberg \& Monahan, 2007; Sumter, Bokhorst, Steinberg, \& Westenberg, 2009) certainly are consistent with this hypothesis. Research has also suggested that higher levels of self-regulation among late adolescents (Gardner, Dishion, \& Connell, 2008) and inhibitory control among younger adolescents (Vitale et al., 2005) conferred protection against deviant peer influences.

Allen, Porter, and McFarland (2006) proposed that susceptibility to influence is a function of autonomy development (i.e., behavior change resulting from interactions with peers is a reflection of adolescents' capacity to self-direct one's behavior and engage in independent thinking). Using an adolescent's ability to maintain his/her viewpoint in a discussion with a best friend as a performance-based measure of peer susceptibility, Allen et al. (2006) revealed that susceptibility was associated longitudinally with psychosocial difficulties (e.g., increases in depressive symptoms and declines in popularity with peers). Conversely, these investigators found that the ability to influence friends was associated with resistance to negative peer pressure and markers of healthy psychosocial adaptation. Further supporting the role of autonomy development in peer influence susceptibility, Bamaca and UmanaTaylor (2006) found a link between self-reported resistance to overt pressure from peers and emotional autonomy from parents in a Mexican American sample of adolescents. Thus, it appears that adolescents' capacity to both influence and be influenced may vary based on success in meeting age-related developmental milestones.

In addition to the study of demographic factors and related constructs, some research examining target adolescents' characteristics has suggested that adolescents' own psychological symptoms may increase their susceptibility to peer influence. Social anxiety (and perhaps other indicators of internalizing distress) has emerged as an especially important variable that increases the likelihood for adolescents to conform to peers, both in longitudinal research examining depression contagion between close friends (Prinstein, 2007) and in an experimental study of adherence to electronic confederates' behavior (Cohen \& Prinstein, 2006). Additionally, difficulties negotiating family relationships also 
appears to enhance susceptibility to peer influence (Jaccard, Blanton, \& Dodge, 2005; Vitaro, Brendgen, \& Tremblay, 2000).

\section{Peer Influence Moderators: Influencer Characteristics}

Characteristics of the influencing peer represent a second class of moderators. Unfortunately, this area has been understudied. Extant research from the last decade suggests that peers high in peer status are more likely than low-status peers to exert socialization effects for aggressive/health-risk behaviors (Cohen \& Prinstein, 2006) and depressive symptoms (Prinstein, 2007). It appears that dissimilarity between characteristics of the influencing peer and characteristics of the target adolescent also may moderate influence, such that greater discrepancies between partners on key traits predicts higher susceptibility (e.g., Simon, Aikins, \& Prinstein, 2008).

Features of an adolescent's friendship group also constitute potentially important moderators of the group's influence effects. In a study of group-level influence in preadolescents, Ellis and Zarbatany (2007) found that groups with greater centrality within the larger peer network were more potent sources of influence for prosocial behavior, relational aggression, school misconduct, and deviant behavior-arguably, characteristics that contribute to or maintain the visibility of the group. Groups low in social preference (i.e., comprised of youth who were rejected by their peers) demonstrated enhanced influence effects for deviant behavior only.

\section{Peer Influence Moderators: Target-Influencer Relationship Characteristics}

A third group of moderators includes relationship attributes between the target and the influencing peer that may alter peer susceptibility. As noted above, the work of Dishion and colleagues has suggested that characteristics of deviant adolescents' friendship interactions, particularly dyadic mutuality, moderates the association between deviant talk and adolescents' antisocial behavior (e.g., Piehler \& Dishion, 2007). Other studies of this decade have examined global relationship quality as a moderator of peer socialization. Generally, results suggest that high levels of positive friendship quality increase peer socialization of depression symptoms (Prinstein, 2007), substance use (Urberg, Luo, Pilgrim, \& Degirmencioglu, 2003), and prosocial behavior (Barry \& Wentzel, 2006). These findings seem to indicate that intimacy, support, and positive affect between friends promote conformity, at least for some behaviors.

Friendship reciprocity, as a possible reflection of the cohesion and affinity between an adolescent target and influencer, also has been considered as a potential moderator of peer influence. Contradictory theories abound, however. On the one hand, if an adolescent desires a relationship (or more equal relationship) with a nonreciprocated peer, she or he might be more inclined to conform to this peer's behavior (see Heilbron \& Prinstein, 2008). On the other hand, reciprocal friendships typically involve stronger relationship qualities that are thought to enhance socialization effects, as discussed above. Research examining friendship reciprocity as a moderator of peer influence has yielded support for both hypotheses (cf. Bot, Engels, Knibbe, \& Meeus, 2005; Hall \& Valente, 2007; Mercken, Candel, Willems, \& de Vries, 2007; Stevens \& Prinstein, 2005).

\section{Peer Influence Moderators: Type of Behavior}

Fourth, research in the last decade has revealed important findings regarding specific behaviors that may be most susceptible to peer socialization effects. This notion first was suggested by Berndt (1979), who hypothesized that susceptibility to pressure depended on the social and legal value associated with the target behavior. Clasen and Brown (1985) later proposed a modified classification of peer influence, urging a conceptualization of the 
process in terms of activity type. A rich literature initiated before this decade indicated that antisocial and unhealthy behaviors are most vulnerable to contagion processes. Recent work has further delineated that certain stages of behavioral engagement (e.g., initiation of smoking behavior or cessation of alcohol and chewing tobacco use; Maxwell, 2002) may be particularly prone to peer influence. Further, research of this decade has suggested that influence may be more salient for some subtypes of behavior; for example, Ryan (2001) found that classmates influenced middle schoolers' academic achievement and intrinsic motivation for school, but not their expected success in school or their beliefs about the importance of school. Espelage, Holt, and Henkel (2003) detected a significant effect of adolescents' peer group on increases in bullying, but not fighting.

\section{Synthesis and Future Directions}

A large and growing number of investigators have examined the factors that increase or decrease the likelihood of influence effects between peers, and these findings are essential toward the development of more precise, targeted intervention efforts. At this stage, current knowledge of moderators is largely descriptive; future examination of these variables should be directed by developmental psychopathology theories. For example, it is likely that research from the past decade has collectively identified variance related to a broader vulnerability construct that renders youth more or less susceptible to influence.

In addition, it should be noted that moderators are variables hypothesized to affect peer influence susceptibility. A more direct approach toward understanding resistance to peer influence would be to study susceptibility as a unique construct. Several approaches for operationalizing and examining peer influence susceptibility are available; however, research still is needed to fully understand this elusive construct (Allen et al., 2006; Steinberg \& Monahan, 2007).

Note also that although much of the work conducted within the last 10 years has been focused on peer influence within normative adolescent populations, there is evidence for iatrogenic effects within mental health group interventions for adolescents (Dodge, Dishion, $\&$ Lansford, 2006). Influence research should continue this examination of moderators that may be particularly relevant for socialization processes in at-risk or clinical populations, with an aim toward effectively alleviating harmful effects for particularly vulnerable youth.

\section{INTEGRATION OF BEHAVIORAL GENETICS, NEUROSCIENCE, AND PEER INFLUENCE RESEARCH}

Similar to a trend seen in behavioral science more broadly, investigations on peer influence have begun to consider biological factors that may be relevant for understanding peer influence. Typical brain development during adolescence-including broad growth in social cognitive skills—orients teens toward the social world and heightens the salience of peers (e.g., Blakemore \& Choudhury, 2006). Research using fMRI and other imaging methods has enabled identification of neural profiles associated with heightened sensitivity to peer influence (Grosbras et al., 2007; Nelson, Leibenluft, McClure, \& Pine, 2005), offering additional insight into the individual (and biologically based) factors which may moderate the association between peers' and adolescents' behavior.

Further, research from the past decade has suggested that genetic liability could be a moderator of the relationship between exposure to peer behavior and adolescents' own behavior. Adolescents have genetically influenced individual differences that render them more or less susceptible to peer influence (i.e., a gene - environment interaction; Rutter \& Silberg, 2002). A study by Harden, Hill, Turkheimer, and Emery (2008) found that the impact of best friends' substance use on target adolescents' use was most pronounced for 
adolescents with the highest genetic vulnerability for using tobacco and alcohol. This interaction also has been observed for other outcomes and at various ages. In two samples of young twins, youth were most likely to be physically aggressive if they were both genetically liable for this behavior and were exposed to highly aggressive peers (Brendgen et al., 2008; van Lier et al., 2007).

Recent research has offered an additional perspective on the biological origins of susceptibility to peer influence. An fMRI study by Grosbras et al. (2007) identified that when 10-year-old participants were exposed to socially relevant and emotionally evocative stimuli, individuals who scored relatively higher on a self-report measure of resistance to peer influence (RPI; Steinberg \& Monahan, 2007) exhibited a different pattern of neural activity compared with children who scored lower on this measure (i.e., children who are less likely to resist peer influences). Specifically, individuals with higher RPI scores showed significantly more connectivity between regions of the brain that process actions of others and areas involved in decision making. Evidence for similar functional connectivity between frontoparietal and prefrontal cortical networks in adolescents (Paus et al., 2008) suggests that resistance to peer influence—as measured by the RPI—is mediated by specific features of the brain.

\section{Synthesis and Future Directions}

These initial studies illustrate a need to further consider biologically based mechanisms and moderators in researchers' conceptualizations of peer influence effects. Behavioral genetics approaches can offer insight into both genetic and environmental causal mechanisms that remain undetected through other methods (Moffitt, 2005). Cognitive neuroscience approaches offer a critical avenue for better understanding adolescents' information processing mechanisms that may mediate peer influence effects. Clearly, more research on this relatively novel approach to the study of peer influence processes will help to further tailor focused prevention and intervention programs aimed to reduce negative influence effects.

\section{CONCLUSION}

Overall, research on peer influence has expanded dramatically within the past decade, offering important conceptual, methodological, and empirical contributions to an exciting and important area of study. Much work is still needed, including continued examination within each of the domains of peer influence research reviewed here. Moreover, there is a very strong need to further understand factors that may be relevant for understanding potential ethnic or cultural differences in peer selection and socialization processes; unfortunately, these issues have been grossly understudied. Continued work utilizing longitudinal designs, particularly involving multiple waves of data, also will be essential in the future to help elucidate reciprocal associations between selection and socialization processes and to illuminate the developmental changes that may underlie the types of behaviors, moderators, and mechanisms that may be especially pertinent at various ages. Large data sets also will help to appropriately examine questions regarding complex social networks, and overlapping relationships, that accurately reflect the true complexity of adolescents' peer interactions. Further, more data are needed to understand the magnitude of peer influence effects, particularly as compared with other risk factors for maladaptive behaviors.

Peer influence processes are reported with remarkable consistency in multiple social science literatures, demonstrating unequivocally that adolescents' peer interactions can have dramatic effects on attitude and behavior development. The opportunity to examine the specific manner in which peer influence processes operate and they ways that these 
processes can be modified or productively harnessed in efforts to improve adolescent wellbeing, is an exciting empirical challenge. The past 10 years have offered stimulating research that should serve to invigorate investigators for decades to come.

\section{References}

Abrams, D.; Hogg, MA. Social identity theory: Constructive and critical advances. London, UK: Harvester Wheatsheat; 1990.

Adamczyk-Robinette SL, Fletcher AC, Wright K. Understanding the authoritative parenting-early adolescent tobacco use link: The mediating role of peer tobacco use. Journal of Youth and Adolescence. 2002; 31:311-318.

Allen, JP.; Antonishak, J. Adolescent peer influences: Beyond the dark side. In: Prinstein, MJ.; Dodge, KA., editors. Understanding peer influence in children and adolescents. New York: Guilford; 2008. p. 141-160.

Allen JP, Porter MR, McFarland FC. Leaders and followers in adolescent close friendships: Susceptibility to peer influence as a predictor of risky behavior, friendship instability, and depression. Development and Psychopathology. 2006; 18:155-172. [PubMed: 16478557]

Bamaca MY, Umana-Taylor AJ. Testing a model of resistance to peer pressure among Mexican-origin adolescents. Journal of Youth and Adolescence. 2006; 35:631-645.

Bandura, A. Social foundations of thought and action: A social cognitive theory. Englewood Cliffs, NJ: Prentice Hall; 1986.

Barry CM, Wentzel KR. Friend influence on prosocial behavior: The role of motivational factors and friendship characteristics. Developmental Psychology. 2006; 42:153-163. [PubMed: 16420125]

Bayer, PJ.; Pintoff, R.; Pozen, DE. Building criminal capital behind bars: Peer effects in juvenile corrections. Yale University Economic Growth Center Discussion Paper No 864. 2004. Retrieved from http://ssrn.com/abstract=441882

Berger, J. Identity signaling, social influence, and social contagion. In: Prinstein, MJ.; Dodge, KA., editors. Understanding peer influence in children and adolescents. New York: Guilford; 2008. p. 181-199.

Berndt TJ. Developmental changes in conformity to peers and parents. Developmental Psychology. 1979; 15:608-616.

Blakemore S, Choudhury S. Development of the adolescent brain: Implications for executive function and social cognition. Journal of Child Psychology and Psychiatry. 2006; 47:296-312. [PubMed: 16492261]

Blanton, H.; Burkley, M. Deviance regulation theory: Applications to adolescent social influence. In: Prinstein, MJ.; Dodge, KA., editors. Understanding peer influence in children and adolescents. New York: Guilford; 2008. p. 94-121.

Bosari B, Carey KB. Peer influences on college drinking: A review of the research. Journal of Substance Abuse. 2001; 20:21-32.

Bot SM, Engels RCME, Knibbe RA, Meeus WHJ. Friend's drinking behaviour and adolescent alcohol consumption: The moderating role of friendship characteristics. Addictive Behaviors. 2005; 30:929-947. [PubMed: 15893090]

Brendgen M, Boivin M, Vitaro F, Bukowski WM, Dionne G, Tremblay RE, et al. Linkages between children's and their friends' social and physical aggression: Evidence for a gene-environment interaction? Child Development. 2008; 79:13-29. [PubMed: 18269506]

Brown, BB. Peer groups and peer cultures. In: Feldman, SS.; Elliott, GR., editors. At the threshold: The developing adolescent. Cambridge, MA: Harvard University Press; 1990. p. 171-196.

Brown, BB.; Bakken, JP.; Ameringer, SW.; Mahon, SD. A comprehensive conceptualization of the peer influence process in adolescence. In: Prinstein, MJ.; Dodge, KA., editors. Understanding peer influence processes in adolescence. New York: Guilford; 2008. p. 17-44.

Brown, BB.; Dolcini, MM.; Leventhal, A. Transformations in peer relationships at adolescence: Implications for health-related behavior. In: Schulenberg, J.; Maggs, JL.; Hurrelmann, K., editors. Health risks and developmental transitions during adolescence. New York: Cambridge University Press; 1997. p. 161-189. 
Burk WJ, Steglich CEG, Snijders TAB. Beyond dyadic interdependence: Actor-oriented models for co-evolving social networks and individual behaviors. International Journal of Behavioral Development. 2007; 31:397-404.

Cillessen AHN, Rose AJ. Understanding popularity in the peer system. Current Directions in Psychological Science. 2005; 14:102-105.

Clasen DR, Brown BB. The multidimensionality of peer pressure in adolescence. Journal of Youth and Adolescence. 1985; 14:451-468.

Cohen GL, Prinstein MJ. Peer contagion of aggression and health-risk behavior among adolescent males: An experimental investigation of effects on public conduct and private attitudes. Child Development. 2006; 77:967-983. [PubMed: 16942500]

Coyne, JC. Thinking interactionally about depression: A radical restatement. In: Joiner, T.; Coyne, JC., editors. The interactional nature of depression. Washington, DC: American Psychological Association; 1999. p. 365-392.

Dishion TJ. Cross-setting consistency in early adolescent psychopathology: Deviant friendships and problem behavior sequelae. Journal of Personality. 2000; 68:1109-1126. [PubMed: 11130734]

Dishion, TJ.; Burraston, B.; Poulin, F. Peer group dynamics associated with iatrogenic effects in group interventions with high-risk young adolescents. In: Erdley, C.; Nangle, DW., editors. The role of friendship in psychological adjustment. San Francisco: Jossey-Bass; 2001. p. 79-92.

Dishion TJ, Dodge KA. Peer contagion in interventions for children and adolescents: Moving towards an understanding of the ecology and dynamics of change. Journal of Abnormal Child Psychology. 2005; 33:395-400. [PubMed: 15957566]

Dishion TJ, Eddy MJ, Haas E, Li F, Spracklen K. Friendships and violent behavior during adolescence. Social Development. 1997; 6:207-223.

Dishion TJ, Nelson SE, Winter CE, Bullock BM. Adolescent friendship as a dynamic system: Entropy and deviance in the etiology and course of male antisocial behavior. Journal of Abnormal Child Psychology. 2004; 32:651-663. [PubMed: 15648531]

Dishion TJ, Nelson SE, Yasui M. Predicting early adolescent gang involvement from middle school adaptation. Journal of Clinical Child and Adolescent Psychology. 2005; 34:62-73. [PubMed: 15677281]

Dishion TJ, Owen LD. A longitudinal analysis of friendships and substance use: Bidirectional influence from adolescence to adulthood. Developmental Psychology. 2002; 38:480-491. [PubMed: 12090479]

Dishion, TJ.; Piehler, TF.; Myers, MW. Dynamics and ecology of adolescent peer influence. In: Prinstein, MJ.; Dodge, KA., editors. Understanding peer influence in children and adolescents. New York: Guilford Press; 2008. p. 72-93.

Dishion TJ, Spracklen KM, Andrews DW, Patterson GR. Deviancy training in male adolescent friendships. Behavior Therapy. 1996; 27:373-390.

Dodge, KA.; Dishion, TJ.; Lansford, JE. Deviant peer influences in programs for youth: Problems and solutions. New York: Guilford Press; 2006.

Dubow, EF.; Huesmann, LR.; Greenwood, D. Media and youth socialization: Underlying processes and moderators of effects. In: Grusec, JE.; Hastings, PD., editors. Handbook of socialization: Theory and research. New York: Guilford; 2007. p. 404-430.

Duncan GJ, Boisjoly J, Kremer M, Levy DM, Eccles J. Peer effects in drug use and sex among college students. Journal of Abnormal Child Psychology. 2005; 33:375-385. [PubMed: 15957564]

Ellis WE, Zarbatany L. Peer group status as a moderator of group influence on children's deviant, aggressive, and prosocial behavior. Child Development. 2007; 78:1240-1254. [PubMed: 17650136]

Erickson K, Crosnoe R, Dombusch S. A social process model of adolescent deviance: Combining social control and differential association perspectives. Journal of Youth and Adolescence. 2000; 29:395-425.

Espelage DL, Holt MK, Henkel RR. Examination of peer group contextual effects on aggressive behavior during early adolescence. Child Development. 2003; 74:205-220. [PubMed: 12625446]

Festinger L. A theory of social comparison processes. Human Relations. 1954; 7:117-140. 
Fowler B, Christakis NA. Dynamic spread of happiness in a large social network: Longitudinal analysis over 20 years in the Framingham Heart Study. British Medical Journal. 2009; 338:1-13.

Gardner TW, Dishion TJ, Connell AM. Adolescent self-regulation as resilience: Resistance to antisocial behavior within the deviant peer context. Journal of Abnormal Child Psychology. 2008; 36:273-284. [PubMed: 17899361]

Gibbons, FX.; Gerrard, M.; Lane, DJ. A social reaction model of adolescent health risk. In: Suls, JM.; Wallson, K., editors. Social psychological foundations of health and illness. Oxford, UK: Blackwell; 2003. p. 107-136.

Granic I, Dishion TJ. Deviant talk in adolescent friendships: A step toward measuring a pathogenic attractor process. Social Development. 2003; 12:314-334.

Grosbras M, Jansen M, Leonard G, McIntosh A, Osswald K, Poulsen C, et al. Neural mechanisms of resistance to peer influence in early adolescence. Journal of Neuroscience. 2007; 27:8040-8045. [PubMed: 17652594]

Hall JA, Valente TW. Adolescent smoking networks: The effects of influence and selection on future smoking. Addictive Behaviors. 2007; 32:3054-3059. [PubMed: 17509770]

Harden KP, Hill JE, Turkheimer E, Emery RE. Gene-environment correlation and interaction in peer effects on adolescent alcohol and tobacco use. Behavior Genetics. 2008; 38:339-347. [PubMed: 18368474]

Harter S, Stocker C, Robinson NS. The perceived directionality of the link between approval and selfworth: The liabilities of a looking glass self-orientation among young adolescents. Journal of Research on Adolescence. 1996; 6:285-308.

Hartup WW. Peer interaction: What causes what? Journal of Abnormal Child Psychology. 2005; 33:387-394. [PubMed: 15957565]

Heilbron N, Prinstein MJ. Peer influence and adolescent non-suicidal self-injury: A theoretical review of mechanisms and moderators. Applied and Preventative Psychology. 2008; 12:169-177.

Heilbron N, Prinstein MJ. Adolescent peer victimization, peer status, suicidal ideation, and nonsuicidal self-injury: Examining concurrent and longitudinal associations. Merrill-Palmer Quarterly. 2010; 56:388-419.

Hergovich A, Sirsch U, Felinger M. Self-appraisals, actual appraisals and reflected appraisals of preadolescent children. Social Behavior and Personality. 2002; 30:603-612.

Hutchinson DM, Rapee RM. Do friends share similar body image and eating problems? The role of social networks and peer influences in early adolescence. Behaviour Research and Therapy. 2007; 45:1557-1577. [PubMed: 17258173]

Jaccard J, Blanton H, Dodge T. Peer influences on risk behavior: An analysis of the effects of a close friend. Developmental Psychology. 2005; 41:135-147. [PubMed: 15656744]

Juvonen, J.; Galvan, A. Peer influence in involuntary social groups: Lessons from research on bullying. In: Prinstein, MJ.; Dodge, KA., editors. Understanding peer influence in children and adolescents. New York: Guilford Press; 2008. p. 225-244.

Juvonen J, Ho AY. Social motives underlying antisocial behavior across middle school grades. Journal of Youth and Adolescence. 2008; 37:747-756.

Kandel D. Similarity in real-life adolescent friendship pairs. Journal of Personality and Social Psychology. 1978; 36:306-312.

Killeya-Jones LA, Costanzo PR, Malone P, Quinlan NP, Miller-Johnson S. Norm-narrowing and selfand other-perceived aggression in early-adolescent same-sex and mixed-sex cliques. Journal of School Psychology. 2007; 45:549-565. [PubMed: 18836510]

Kobus K. Peers and adolescent smoking. Addiction. 2003; 98:37-55. [PubMed: 12752361]

Laursen, B.; Popp, D.; Burk, WJ.; Kerr, M.; Stattin, H.; Card, NA., et al. Modeling dyadic and interdependent data in the developmental and behavioral sciences. New York: Routledge/Taylor \& Francis Group; 2008. Incorporating interdependence into developmental research: Examples from the study of homophily and homogeneity; p. 11-37.

Lavallee KL, Bierman KL, Nix RL. The impact of first-grade 'friendship group' experiences on child social outcomes in the Fast Track Program. Journal of Abnormal Child Psychology. 2005; 33:307324. [PubMed: 15957559] 
Maddock J, Glanz K. The relationship of proximal normative beliefs and global subjective norms to college students' alcohol consumption. Addictive Behaviors. 2005; 30:315-323. [PubMed: 15621402]

Marshal MP, Chassin L. Peer influence on adolescent alcohol use: The moderating role of parental support and discipline. Applied Developmental Science. 2000; 4:80-88.

Maxwell KA. Friends: The role of peer influence across adolescent risk behaviors. Journal of Youth and Adolescence. 2002; 31:267-277.

Mayeux L, Sandstrom MJ, Cillessen AHN. Is being popular a risky proposition? Journal of Research on Adolescence. 2008; 18:49-74.

Mercken L, Candel M, Willems P, de Vries H. Disentangling social selection and social influence effects on adolescent smoking: The importance of reciprocity in friendships. Addiction. 2007; 102:1483-1492. [PubMed: 17610538]

Moffitt TE. The new look of behavioral genetics in developmental psychopathology: Geneenvironment interplay in antisocial behaviors. Psychological Bulletin. 2005; 131:533-554. [PubMed: 16060801]

Monahan KC, Steinberg L, Cauffman E. Affiliation with antisocial peers, susceptibility to peer influence, and antisocial behavior during the transition to adulthood. Developmental Psychology. 2009; 45:1520-1530. [PubMed: 19899911]

Nelson EE, Leibenluft E, McClure EB, Pine DS. The social re-orientation of adolescence: A neuroscience perspective on the process and its relation to psychopathology. Psychological Medicine. 2005; 35:163-174. [PubMed: 15841674]

Nock MK, Prinstein MJ. Contextual features and behavioral functions of self-mutilation among adolescents. Journal of Abnormal Psychology. 2005; 114:140-146. [PubMed: 15709820]

Otten R, Engels RCME, Prinstein MJ. A prospective study of perception in adolescent smoking. Journal of Adolescent Health. 2009; 44:478-484. [PubMed: 19380096]

Parkhurst JT, Hopmeyer A. Sociometric popularity and peer-perceived popularity: Two distinct dimensions of peer status. The Journal of Early Adolescence. 1998; 18:125-144.

Patterson GR, Dishion TJ, Yoerger K. Adolescent growth in new forms of problem behavior: Macroand micro-peer dynamics. Prevention Science. 2000; 1:3-13. [PubMed: 11507792]

Paus T, Toro R, Leonard G, Lerner JV, Lerner RM, Perron M, et al. Morphological properties of the action-observation cortical network in adolescents with low and high resistance to peer influence. Social Neuroscience. 2008; 3:303-316. [PubMed: 18979383]

Perkins HW, Haines MP, Rice R. Misperceiving the college drinking norm and related problems: A nationwide study of exposure to prevention information, perceived norms and student alcohol misuse. Journal of Studies on Alcohol. 2005; 66:470-478. [PubMed: 16240554]

Piehler TF, Dishion TJ. Interpersonal dynamics within adolescent friendships: Dyadic mutuality, deviant talk, and patterns of antisocial behavior. Child Development. 2007; 78:1611-1624. [PubMed: 17883451]

Popp D, Laursen B, Kerr M, Stattin H, Burk WK. Modeling homophily over time with an actor-partner interdependence model. Developmental Psychology. 2008; 44:1028-1039. [PubMed: 18605832]

Poteat VP. Peer group socialization of homophobic attitudes and behavior during adolescence. Child Development. 2007; 78:1830-1842. [PubMed: 17988324]

Poteat VP, Espelage DL, Green HD Jr. The socialization of dominance: Peer group contextual effects on homophobic and dominance attitudes. Journal of Personality and Social Psychology. 2007; 92:1040-1050. [PubMed: 17547487]

Prentice, DA. Mobilizing and weakening peer influence as mechanisms for changing behavior. In: Prinstein, MJ.; Dodge, KA., editors. Understanding peer influence in children and adolescents. New York: Guilford; 2008. p. 161-180.

Prentice, DA.; Miller, DT. Pluralistic ignorance and the perpetuation of social norms by unwitting actors. In: Zanna, M., editor. Advances in experimental social psychology. Vol. 28. San Diego: Academic Press; 1996. p. 161-209.

Prinstein MJ. Moderators of peer contagion: A longitudinal examination of depression socialization between adolescents and their best friends. Journal of Clinical Child and Adolescent Psychology. 2007; 36:159-170. [PubMed: 17484689] 
Prinstein MJ, Boergers J, Spirito A. Adolescents' and their friends' health-risk behavior: Factors that alter or add to peer influence. Journal of Pediatric Psychology. 2001; 26:287-298. [PubMed: 11390571]

Prinstein MJ, Cillessen AHN. Forms and functions of adolescent peer aggression associated with high levels of peer status. Merrill-Palmer Quarterly. 2003; 49:310-342.

Prinstein, MJ.; Guerry, JD.; Browne, CB.; Rancourt, D.; Nock, MK. Understanding nonsuicidal selfinjury: Origins, assessment, and treatment. Washington, DC: American Psychological Association; 2009. Interpersonal models of nonsuicidal self-injury; p. 79-98.

Prinstein MJ, Meade CS, Cohen GL. Adolescent oral sex, peer popularity, and perceptions of best friends' sexual behavior. Journal of Pediatric Psychology. 2003; 28:243-249. [PubMed: 12730281]

Rancourt, D.; Prinstein, MJ. Mechanisms of peer socialization: Imitation/modeling and social comparison models of adolescent girls' weight-related behaviors. In: Rancourt, D., editor. How and why does peer influence occur?: Socialization mechanisms from a developmental perspective. Chicago: Society for Research on Adolescence; 2008.

Rancourt D, Prinstein MJ. Peer status and victimization as possible reinforcements of adolescent girls' and boys' weight-related behaviors and cognitions. Journal of Pediatric Psychology. 2010; 35:354-367. [PubMed: 19667053]

Rose AJ, Carlson W, Waller EM. Prospective associations of co-rumination with friendship and emotional adjustment: Considering the socioemotional trade-offs of co-rumination. Developmental Psychology. 2007; 43:1019-1031. [PubMed: 17605532]

Rose AJ, Swenson LP, Waller EM. Overt and relational aggression and perceived popularity: Developmental differences in concurrent and prospective relations. Developmental Psychology. 2004; 40:378-387. [PubMed: 15122964]

Rubin, KH.; Bukowski, WM.; Parker, JG. Peer interactions, relationships, and groups. In: Eisenberg, N.; Damon, W.; Lerner, RM., editors. Handbook of child psychology: Vol. 3, Social, emotional, and personality development. 6. Hoboken, NJ: John Wiley \& Sons Inc; 2006. p. 571-645.

Rutter M, Silberg J. Gene-environment interplay in relation to emotional and behavioral disturbance. Annual Review of Psychology. 2002; 53:463-490.

Ryan AM. The peer group as a context for the development of young adolescent motivation and achievement. Child Development. 2001; 72:1135-1150. [PubMed: 11480938]

Sacco, WP. A social-cognitive model of interpersonal processes in depression. In: Joiner, T.; Coyne, JC., editors. The interactional nature of depression. Washington, DC: American Psychological Association; 1999. p. 329-362.

Simon VA, Aikins JW, Prinstein MJ. Romantic partner selection and socialization during early adolescence. Child Development. 2008; 79:1676-1692. [PubMed: 19037942]

Snyder J, Schrepferman L, McEachern A, Barner S, Johnson K, Provines J. Peer deviancy training and peer coercion: Dual processes associated with early-onset conduct problems. Child Development. 2008; 79:252-268. [PubMed: 18366422]

Snyder J, Schrepferman L, Oeser J, Patterson G, Stoolmiller M, Johnson K, et al. Deviancy training and association with deviant peers in young children: Occurrence and contribution to early-onset conduct problems. Development and Psychopathology. 2005; 17:397-413. [PubMed: 16761551]

Steinberg L, Monahan KC. Age differences in resistance to peer influence. Developmental Psychology. 2007; 43:1531-1543. [PubMed: 18020830]

Stevens EA, Prinstein MJ. Peer contagion of depressogenic attributional styles among adolescents: A longitudinal study. Journal of Abnormal Child Psychology. 2005; 33:25-38. [PubMed: 15759589]

Stormshak EA, Comeau CA, Shepard SA. The relative contribution of sibling deviance and peer deviance in the prediction of substance use across middle childhood. Journal of Abnormal Child Psychology. 2004; 32:635-649. [PubMed: 15648530]

Sumter SR, Bokhorst CL, Steinberg L, Westenberg PM. The developmental pattern of resistance to peer influence in adolescence: Will the teenager ever be able to resist? Journal of Adolescence. 2009; 32:1009-1021. [PubMed: 18992936] 
Swann, WB, Jr. Self-verification: Bringing social reality into harmony with the self. In: Suls, J.; Greenwald, AG., editors. Social psychological perspectives on the self. Vol. 2. Hillsdale, NJ: Erlbaum; 1983. p. 33-66.

Urberg KA, Degirmencioglu SM, Tolson JM, Halliday-Scher K. The structure of adolescent peer networks. Developmental Psychology. 1995; 31:540-547.

Urberg KA, Luo Q, Pilgrim C, Degirmencioglu SM. A two-stage model of peer influence in adolescent substance use: Individual and relationship-specific differences in susceptibility to influence. Addictive Behaviors. 2003; 28:1243-1256. [PubMed: 12915166]

van der Vorst H, Engels RCME, Meeus W, Dekovic M, Van Leeuwe J. Similarities and bi-directional influences regarding alcohol consumption in adolescent sibling pairs. Addictive Behaviors. 2007; 32:1814-1825. [PubMed: 17289280]

van Lier P, Boivin M, Dionne G, Vitaro F, Brendgen M, Koot H, et al. Kindergarten children's genetic vulnerabilities interact with friends' aggression to promote physical aggression. Journal of the American Academy of Child and Adolescent Psychiatry. 2007; 46:1080-1087. [PubMed: 17667486]

Van Zalk MHW, Kerr M, Branje SJT, Stattin H, Meeus WHJ. It takes three: Selection, influence, and de-selection processes of depression in adolescent friendship networks. Developmental Psychology. 2010; 46:927-938. [PubMed: 20604612]

Verkooijen KT, de Vries NK, Nielsen GA. Youth crowds and substance use: The impact of perceived group norm and multiple group identification. Psychology of Addictive Behaviors. 2007; 21:5561. [PubMed: 17385955]

Vitale JE, Newman JP, Bates JE, Goodnight J, Dodge KA, Pettit GS. Deficient behavioral inhibition and anomalous selective attention in a community sample of adolescents with psychopathic traits and low-anxiety traits. Journal of Abnormal Child Psychology. 2005; 33:461-470. [PubMed: 16118992]

Vitaro F, Brendgen M, Tremblay RE. Influence of deviant friends on delinquency: Searching for moderator variables. Journal of Abnormal Child Psychology. 2000; 28:313-325. [PubMed: 10949957]

Wentzel KR, Barry CM, Caldwell KA. Friendships in middle school: Influences on motivation and school adjustment. Journal of Educational Psychology. 2004; 96:195-203. 